\title{
Pathogenesis of Brucella spp.
}

\author{
Mariana N. Xavier ${ }^{1}$, Tatiane A. Paixão ${ }^{1}$, Andréas B. den Hartigh $^{2}$, Renée M. Tsolis ${ }^{2}$ and Renato L. Santos ${ }^{*}, 1$ \\ ${ }^{I}$ Departamento de Clínica e Cirurgia Veterinária, Escola de Veterinária, Universidade Federal de Minas Gerais, \\ 31270-901 Belo Horizonte, MG, Brazil \\ ${ }^{2}$ Department of Medical Microbiology and Immunology, University of California, One Shields Avenue, Davis, \\ California 95616, USA
}

\begin{abstract}
Brucellosis is one of the most important zoonotic diseases worldwide, resulting in serious economic losses and public health issues. It is caused by intracellular Gram-negative bacteria of the genus Brucella, which are responsible for a debilitating disease in humans and a chronic infection in domestic animals. The present article considers the pathogenesis of Brucella spp., with the goal to cover clinical aspects of the disease in the different mammalian species along with the target cells used by this pathogen to survive inside the host. Additionally, important molecular mechanisms used by Brucella to invade and persist inside the hosts target cells are also discussed.
\end{abstract}

Keywords: Brucellosis, pathogenesis, Brucella.

\section{INTRODUCTION}

Brucellosis is one of the most widespread zoonotic diseases globally, with an estimated 500,000 new human cases each year. The disease is caused by Gram negative bacteria of the genus Brucella, which are facultative intracellular coccobacilli that belong to the $\alpha 2-$ Proteobacteriacea family [1]. In spite of more than $94 \%$ similarity amongst the members of the genus $[2,3]$, bacteria of the genus Brucella have different host preferences. Therefore, Brucella spp. are capable of causing disease in a variety of animal species, including humans (Table 1).

Table 1. Zoonotic Potential and Host Preference of Brucella Species

\begin{tabular}{|c|c|c|}
\hline Species & Zoonotic Potential & Host Preference \\
\hline \hline Brucella melitensis & High & Sheep, goat \\
\hline Brucella abortus & Moderate & Cattle \\
\hline Brucella suis & Moderate & Pig \\
\hline Brucella canis & Mild & Dog \\
\hline Brucella ovis & Absent & Sheep \\
\hline Brucella neotomae & Absent & $\begin{array}{c}\text { Desert wood rat } \\
\text { (Neotomae lepida) }\end{array}$ \\
\hline Brucella ceti & Mild & \begin{tabular}{c} 
Cetaceans \\
\hline Brucella pinnipedialis
\end{tabular} \\
\hline Brucella microti & Mild & Seals \\
\hline
\end{tabular}

*Address correspondence to this author at the Departamento de Clínica e Cirurgia Veterinária, Escola de Veterinária, Universidade Federal de Minas Gerais. Av. Antonio Carlos, 6627. 31270-901 Belo Horizonte, MG, Brazil; Tel: 55-31-3409-2239; Fax: 55-31-3409-2230; E-mail: rsantos@vet.ufmg.br
Division of the genus into six classical species Brucella, namely $B$. melitensis, B. abortus, B. suis, B. canis, B. ovis and $B$. neotomae, is still widely used due to historical and clinical reasons [4]. B. melitensis, B. suis and B. abortus are considered the most pathogenic species for humans and have small ruminants, pigs and cattle as preferential hosts, respectively [5]. In addition, two recently identified Brucella species isolated from marine mammals, $B$. ceti and $B$. pinnipedialis, can also cause human brucellosis [6]. Importantly, $B$. canis, a pathogen of dogs, has a comparatively low zoonotic potential, while $B$. neotomae and $B$. ovis, that infect desert rats and sheep and, respectively, are not associated with human disease [5].

Human brucellosis is considered as a life-threatening debilitating disease characterized by weakness, fever, malaise, arthritis, osteomyelitis, endocarditis or meningoencephalitis [7]. In domestic animals, the disease occurs as a chronic infection that results in placentitis and abortion in pregnant females [8,9] or orchitis and epididymitis in males [9].

An important aspect of Brucella infection is its ability to persist and replicate within phagocytic cells of the reticuloendothelial system as well as in non-phagocytic cells such as trophoblasts. This ability involves a temporary fusion of the Brucella-containing vacuole with the lysosome, and subsequent exclusion of the lysosomal proteins [10]. Following this process, the Brucella-containing vacuole becomes associated with the endoplasmic reticulum. These endoplasmic reticulum-associated compartments are the niche for intracellular replication of Brucella in macrophages, epithelial cell lines and placental trophoblasts [11-14]. Once inside this compartment, the bacteria can establish chronic infection.

This review describes the pathogenesis of Brucella infection in the light of recently generated knowledge regarding host-pathogen interactions and molecular mechanisms of intracellular survival and pathogenesis. 


\section{HOST-PATHOGEN INTERACTIONS AND DISEASE MANIFESTATION}

Human brucellosis is considered one of the most important zoonotic diseases worldwide $[15,16]$. Although $B$. abortus, B. suis and B. canis are potential agents of this disease, $B$. melitensis is considered the most virulent Brucella for humans with a few organisms (10 to 100) being sufficient to cause a debilitating chronic infection [17]. In most cases, human infections occur through ingestion of contaminated milk and unpasteurized dairy products. However, occupational exposure of mucosa or skin abrasions to fluids and tissues from aborted fetuses of infected animals or carcass is also an important source of infection [17, 18]. The efficient transmission of Brucella via inhalation of contaminated dust or aerosols makes brucellosis one of the most common laboratory-acquired infections worldwide and spurred the original weaponization of Brucella spp. by the United States and the former Soviet Union in the 1950's.

Human brucellosis is a life-threatening disease that may have variable clinical presentations [19]. After exposure to the bacteria, clinical manifestations may appear within 5 to 60 days [20]. Most infected patients present with acute disease consisting of general symptoms, such as fever, malaise, sweats and lymphadenopathy and/or hepatosplenomegaly. However, a subset of patients develops chronic brucellosis, a more severe form of the disease that can be associated with osteo-articular signs including spondylitis, arthritis and osteomyelitis, or genitourinary changes, such as orchitis, epididymitis, glomerulonephritis and kidney abscesses [18, 19]. Life-threatening complications comprise, in descending order of frequency, neurobrucellosis, liver abscesses, and endocarditis [17].

Brucellosis in small ruminants is mainly caused by $B$. melitensis, although this pathogen may also infect cattle and other ruminants [21]. This pathogen, which has three different biovars [22], is endemic in several parts of the world, particularly biovar 3 in Mediterranean and Middle Eastern countries [23]. Some Latin American countries are also seriously affected by biovar 1, especially Mexico, Peru and Northern Argentina [24]. B. melitensis infection of goats and sheep is characterized by abortion, reduced milk yield, and orchitis. Although sexually mature animals of both genders are equally susceptible to the disease, the predominant sign of acute infection is reproductive failure with abortion in the last trimester and birth of weak offspring. In small ruminants, transmission of the disease often occurs by contact of susceptible animals with contaminated secretions from the female genital tract [25]. Approximately two thirds of acute natural $B$. melitensis infections of goats during pregnancy lead to infection of the udder and excretion of the bacteria in milk during the subsequent lactation. Progressively, intermittent shedding of the agent in milk occurs in animals with persistent infection of the udder. B. melitensis may cause inflammation of the mammary tissue, which is the most probable cause of reduced milk production in infected animals. However, clinical signs of mastitis are usually not detectable in naturally infected goats [25].

Cattle are considered to be the preferential host for $B$. abortus, but the organism can also affect buffaloes, camels, deer, dogs, horses, goats, sheep, and man [26]. This Brucella species is classified into seven different biovars, namely biovars 1-6 and 9. Outbreaks of brucellosis in dairy herds result in decreased milk production, while they increase somatic cell count in milk, abortion and post-partum metritis [27]. Therefore, bovine brucellosis is primarily a disease of cows, with the organism being isolated from the udder, uterus, and lymphoid organs of infected animals [8, 28]. Although abortion during the last trimester of gestation is considered the predominant clinical sign of the disease, infected cows usually abort only once, giving birth to weak or even healthy calves in subsequent gestations. Importantly, some infected cows will not exhibit any symptoms of the disease and give birth to normal calves [29]. B. abortusinduced abortion is associated with necro-hemorrhagic placentitis and fetal lesions, particularly fibrinous pleuritis and pericarditis, and interstitial pneumonia [28]. As described for B. melitensis, B. abortus infection may lead to a mild to moderate interstitial mastitis, resulting in intermittent shedding of the pathogen in the milk [28]. Transmission of bovine brucellosis occurs mainly after abortion or parturition of infected cows when susceptible cattle may have contact with contaminated fetuses, fetal membranes, and uterine secretions [29]. In bulls, B. abortus is a common cause of orchitis that is often associated with a seminal vesiculitis and epididymitis. Infected bulls usually do not play a major role in spreading the disease. Infection in males may result in either temporary or permanent infertility, depending on the intensity of the lesions [30].

Porcine brucellosis caused by B. suis biovars 1, 2 and 3, is considered an important reemerging disease of domestic and wild pigs. However, this pathogen may also affect other species such as cattle, horses, rabbits, dogs, and humans [31, 32]. Biovars 1 and 3, which have pathogenic potential for humans, occur in Europe, North, South and Central America, Southern Asia and Pacific islands [33]. B. suis infection in pigs often does not result in clinical signs, making clinical diagnosis a very difficult task. In clinical cases, porcine brucellosis is primarily characterized by a genital disease with abortions. However, the bacteria may also affect other organs, particularly bones and joints [34]. Therefore, the disease is considered a herd problem with pigs of all ages being affected, albeit with a higher incidence of infection in adults. Transmission of the disease in pigs occurs by both venereal and oral routes, with $B$. suis being secreted in large numbers, for long periods in the semen and urine as well as in uterine discharges, and milk [25]. The most important clinical signs in sows are infertility, irregular estrus, abortion in any stage of gestation, and birth of weak piglets with a high neonatal mortality rate. Porcine brucellosis is the only disease in which reproductive failure in sows is accompanied by orchitis in boars and osteo-articular disorders such as arthritis, osteomyelitis, spondylitis, and paralysis [35]. Albeit orchitis and epididimitis are the most common lesions in boars, the infection occasionally may be restricted to sexual glands and may not result in impaired fertility. However, even these asymptomatic cases may result in shedding of the organism in the semen with potential for venereal transmission of infection [36].

Canine brucellosis, caused by $B$. canis, usually affects domestic dogs, wild carnivores, and rarely other domestic animals [37]. The disease occurs mostly in Central and South America. B. canis is also considered a zoonotic agent, but 
infections are uncommon and usually mild. Most natural human infections have been acquired through close contact with infected dogs or accidental laboratory contamination [37]. In dogs, transmission of the disease usually occurs by breeding or ingestion of contaminated placental tissues, aborted fetuses or vaginal secretions from infected bitches. Importantly, B. canis may be shed for long periods in semen or vaginal secretion after occurrence of abortion [38, 39]. In bitches, the predominant clinical sign is abortion after 45-55 days of gestation. Occasionally, early embryonic death and reabsorption, or abortion 10-20 days after mating, may occur [37]. Infected males have unilateral or bilateral epididymitis and orchitis as the most important clinical signs, often leading to infertility. Semen from infected dogs usually contains large numbers of abnormal sperm and inflammatory cells, especially during the first three months after infection. Chronically infected males may have azospermia, or reduced numbers of immature sperm [40]. In contrast to other Brucella infections, B. canis infection of dogs results in prolonged bacteremia. Therefore, blood culture is a valuable diagnostic approach in canine brucellosis, as opposed to other Brucella/host combinations [38].

Ovine brucellosis caused by $B$. ovis infection is a disease of sheep that occurs in most sheep-raising areas worldwide such as Australia, New Zealand, North and South America, South Africa, and many countries in Europe [41]. B. ovis primarily causes epididymitis in sexually mature rams, and occasionally abortion in ewes [42]. Poor semen quality characterized by decreased sperm concentration and sperm abnormalities is often associated with early infections (Fig. 1) [43]. With the progression of the disease, palpable lesions may develop in the epididymis, which may be unilaterally or, occasionally, bilaterally affected [42]. It is noteworthy that chronically affected rams usually have regression of the lesions in the epidydimis and most infected rams never develop any clinical sign of the disease [41]. In addition, those asymptomatic rams may shed $B$. ovis in the semen for long periods, thus increasing the risk of spreading infection in the herd [41]. Transmission can occur by direct contact between rams kept in the same premises for prolonged periods of time or through ewes that have mated with an infected ram prior to a susceptible one during the same mating season $[44,45]$. In ewes, B. ovis can uncommonly cause abortion associated with placentitis beginning at 30 days of gestation. Infected ewes may give birth to weak lambs with a high neonatal mortality rate [46].

Since the 1990's, marine strains of Brucella have been isolated from a variety of marine mammal species, including seal (Phoca vitulina), dolphins (Tursiops truncatus; Delphinus delphis; Lagenorhynchus acutus; Stenella coeruleoalba), whale (Balaenoptera acutorostrata), and other species [47-51]. First classified as B. maris, the marine isolates of Brucella are now putatively divided into two species: $B$. ceti and $B$. pinnipedialis, referring to isolates from cetaceans and seals, respectively [52]. As described for other species of the genus, some marine isolates are capable of infecting humans, with reported cases associated with neurological disorders $[53,54]$. It is believed that transmission to human occurs through direct contact with marine mammals or ingestion of infected animals. However, there are reports of human brucellosis caused by marine

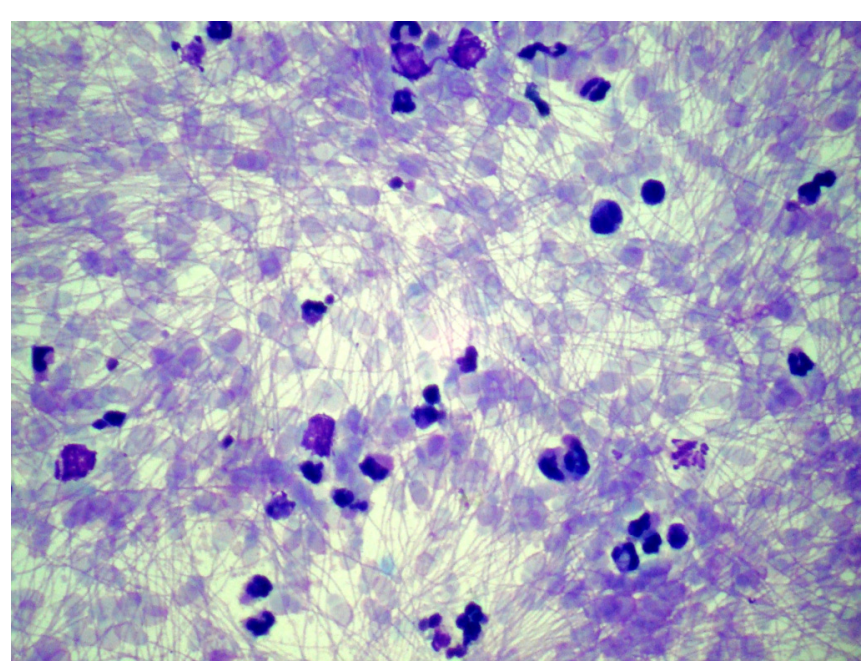

Fig. (1). Semen smear from a ram infected with Brucella ovis containing several inflammatory cells (predominantly neutrophils).

isolates in which there was no evidence of contact of the patient with marine animals [53-55], which raises the question of whether additional reservoirs of these Brucella species contribute to human infections.

In marine mammals infected with Brucella, transmission of the disease may occur through mucosa and injured skin, direct contact, or by the oral route due to ingestion of other infected marine mammals [56]. Vertical or horizontal transmission to fetus also has to be considered as a route of infection, since Brucella has been isolated in fetal tissues and in milk from dolphins [54, 57]. Marine animals affected by brucellosis develop pathological changes that include skin abscesses, hepatic and splenic necrosis or/and histiocytic inflammation, meningitis, discospondylitis, and abortion [49]. Importantly, non suppurative meningoencephalitis has been described as the most consistent histological change in dolphins with neurological signs and positive serology and immumohistochemistry to Brucella sp. [54, 58]. Additionally, marine Brucella species are capable of infecting terrestrial mammal species as demonstrated by experimental infection of cattle [59].

Recently, a previously undescribed Brucella species was associated, with two cases of second semester of gestation stillbirth in a baboon colony [60]. Apparently less pathogenic species of Brucella have also been reported. $B$. neotomae, firstly discovered in 1947 [61], is known to infect only the desert wood rat under natural conditions in the USA, and no other cases in addition to the original isolation have been reported. In 2000, a new Brucella isolate named $B$. microti was isolated from systemically infected common voles (Microtus arvalis) in South Moravia, Czech Republic [62]. Later on, B. microti was isolated from mandibular lymph nodes of wild red foxes (Vulpes vulpes) hunted in Austria [63]. Those facts indicate that there is still a wide range of information to be explored regarding the genus Brucella and its host range. Further, the pathogenic potential of these recent isolates for humans or other (domestic?) animal species have yet to be investigated.

\section{TARGET CELLS}

Brucella spp. is capable of invading and surviving in both phagocytic [64] and non-phagocytic host cells [65]. 
Macrophages (Fig. 2A), dendritic cells (DCs), and trophoblasts (Fig. 2B) represent the major target cells for Brucella, according to clinical manifestation of brucellosis in experimental and natural hosts, characterized by persistent infectious in lymphoid tissues and inflammatory lesions in the reproductive tract of pregnant females [28, 66, 67]. Bacterial entrance, survival and replication have been intensively investigated in phagocytes, but these mechanisms are poorly characterized in trophoblasts, which represents an important gap in our understanding of the disease and transmission in the natural host species.

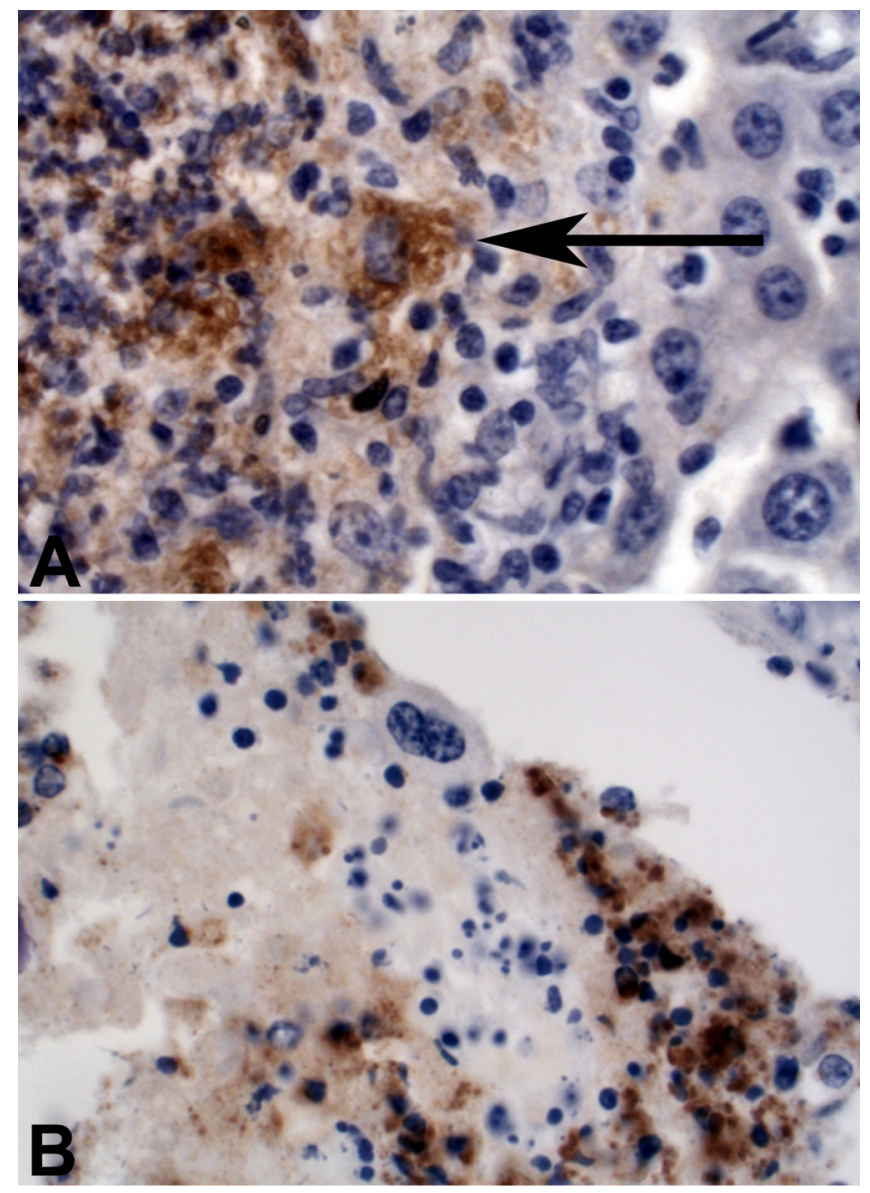

Fig. (2). (A) Mouse. Hepatic microgranuloma with immunostained Brucella spp. (arrow). (B) Cow. Chorionic membrane with trophoblastic cells containing myriad of predominantly intracellular immunostained Brucella abortus. 50x.

In order to reach its target cells, Brucella needs to cross mucosal barriers of the respiratory, genitourinary or digestive tract, where it undergoes phagocytosis by resident macrophages and DCs, resulting in dissemination of the organism to lymphoid and reproductive organs [68,69]. Invasion through the digestive tract is associated with epithelial transmigration of bacteria preferentially through $\mathrm{M}$ cells. Intra-epithelial phagocytes may also transport Brucella from the intestinal lumen to the lamina propria [69-71].

In macrophages, Brucella is internalized by phagocytosis that requires a moderate recruitment of actin filaments upon activation during interaction of Brucella and receptors on the surface of the macrophage cell membrane. Opsonized Brucella is internalized via $\mathrm{FC}$ or complement receptors whereas non-opsonized bacteria interact with lectin and fibronectin receptors [72]. Non-opsonized Brucella can survive and replicate inside cells; in contrast, opsonization of bacteria or IFN $\gamma$-activation of macrophages enhance intracellular killing of bacteria inside the host cell [73, 74]. Lipids rafts, which are cholesterol-rich microdomains in the cell membrane of macrophages, also participate in bacterial internalization, and additionally these rafts contribute to directing intracellular trafficking of bacteria $[75,76]$. Soon after internalization, the Brucella-containing phagosome interacts with early and late endosomes. The majority of phagocytosed Brucella is destroyed by bactericidal action of free radicals of oxygen, nitric oxide and enzymes inside phagolysosomes. However, a certain number of bacteria resists these bactericidal mechanisms, and after transient fusion with the lysosome can actively exclude lysosomal proteins and redirect the $\mathrm{BCV}$ to the endoplasmic reticulum, where the organism is capable of replicating $[10,14,77-80]$. Importantly, acidification of the Brucella-containing phagosome does not injure the bacteria, but it triggers expression of bacterial genes that are essential for intracellular survival during the early stages of infection [81, 82].

DCs are other phagocytes for which Brucella has a marked tropism, being infected more efficiently than macrophages. Bacteria are able to survive and replicate in DCs similarly to macrophages, although intracellular growth tends to be more prominent in DCs [67]. Furthermore, bacteria can inhibit maturation of DCs compromising DC antigen presentation and cytokine secretion [70, 83, 84]. As a result, DCs have two important aspects which transform them in excellent carriers for Brucella: high tolerance for bacteria development, and migratory properties which could support pathogen spreading [67]. Importantly, DC assays have been conducted in human and mice cell lines. Therefore, differences in the pathogen behavior regarding these cells related to the host species may be observed.

The behavior of Brucella in non-phagocytic cells has been better investigated in epithelial cell lines [13, 85-88]. Although Brucella is capable of invading epithelial $[85,86$, $88]$ and trophoblatic cells $[89,90]$, it is much less invasive than other facultative intracellular bacterial pathogens such as Salmonella enterica [91]. No specific receptors for Brucella have been identified in non-phagocytic cells, but there is evidence that some Brucella molecules can contribute to cellular adhesion and invasion [92-94]. Brucella invades epithelial cells via recruitment of actin filaments and rearrangement of the host cell membrane. Internalization of the organism involves activation of regulatory proteins of the cytoskeleton, named small GTPases of the subfamily Rho, including Rho, Rac and Cdc42. In addition, mediators of cell signaling pathways, such as cyclic GMP, PIP3-kinase, tyrosine kinase, and mitogen-activated protein (MAP) kinases, also play a role in internalization acting as second messengers for signals from the GTPases [88, 95]. Intracellular trafficking of Brucella in epithelial cells is similar to that observed in phagocytes [64, 65]. Fluorescence microscopy studies demonstrated that Brucella traffics initially in early phagosome expressing small GTP-binding protein Rab 5 and early endosomal antigen 1 (EEA1) markers [13, 95], progressing towards autophagosomes containing the lysosome associated membrane glycoprotein 1 (LAMP1) and then to the rough 
endoplasmic reticulum-associated compartments that have markers such as calreticulin and $\sec 61 \beta[13,65,87,96]$. Therefore, Brucella traffics from the initial phagosome towards a vacuole composed by membranes of the rough endoplasmic reticulum, which is the optimal site for its replication $[12,13,87]$.

Trophoblastic cells are key target cell of Brucella infection during late phase of gestation in ruminants $[27,28$, 68]. Growth of Brucella inside trophoblasts is apparently enhanced in the presence of high concentrations of steroid hormones and erythritol during the final third of gestation $[97,98]$. The capacity to replicate rapidly and extensively in trophoblasts can compromise the integrity of the placenta and infection of fetus, resulting in abortion or birth of weak offspring [28, 99]. In addition, hormonal changes in infected placentas may affect the occurrence of abortion since an increase in prostaglandin $2 \alpha$, estrogen and cortisol, and decrease in progesterone levels mimic what happens during parturition [100].

\section{MOLECULAR PATHOGENESIS}

The pathogenic potential of Brucella spp. is highly dependent on its ability to enter and survive within host cells. Brucella does not have classic virulence factors such as exotoxins, capsule, or endotoxic lipopolysaccharide (LPS) [101]. The major virulence mechanisms of Brucella already identified are those required for host cell invasion and intracellular survival or replication [81, 102-104].

A successful entry of Brucella into the host is a crucial step in establishing infection. Considering that the digestive tract is the main entrance route of Brucella, some studies investigated possible virulence factors involved on successful infection through the digestive tract [71, 105107]. The genes that encode urease are required for establishment of infection by B. suis, B. abortus and $B$. melitensis $[71,105,106]$. Urease is a multi-subunit enzyme, involved in nitrogen metabolism, which causes increase of $\mathrm{pH}$ due ammonia production as a result of urea hydrolysis [108]. Brucella has two non-adjacent operons of urease and the ure 1 is responsible for urease activity and its inactivation cause attenuation of strains in mice when the organism is inoculated via the digestive tract $[105,106]$. The role of Brucella urease in inhibition of phagosome acidification by ammonia has not been demonstrated [106]. Apparently, the type IV secretion system (T4SS) and LPS are also required to establishment of gastrointestinal infection, although mutant strains still have ability to go across intestinal mucosa via $\mathrm{M}$ cells similar to virulent strain (Fig. 3) [71]. Bile salt hydrolases may be other bacterial enzyme essential to Brucella infecting mice via oral route. The deletion of choloylglycine hydrolase gene in $B$. abortus causes impairment of bacterial growth in medium containing bile salts and attenuation in mice after ten days of intragastric infection [107].

During internalization, Brucella relies on a twocomponent regulator system, BvrR/BvrS that regulates expression of outer membrane proteins (OMPs) involved in invasion of host cells $[102,109]$. The two components of this system are BvrR, a regulator protein, and BvrS, a sensor protein with histidine-kinase activity. This regulator system is required for recruitment of GTPases and actin filaments, and for maintaining the integrity of the bacterial outer membrane [102, 109]. Mutant strains lacking BvrR/BvrS are unable to invade phagocytic and non-phagocytic cells because they do not recruit GTPases, particularly Cdc42. This regulator system is also important for intracellular survival, since mutant strains are unable to inhibit phagosome-lysosome fusion [102, 110].

An additional mechanism employed by Brucella to avoid fusion of the bacteria-containing vacuole with lysosomes in macrophages are cyclic $\beta 1,2$-glucans [103]. Glucans are constituents of the bacterial periplasm with osmoregulatory and cholesterol sequestering activity and are required for survival of Brucella in non-phagocytic cells and in vivo in mice. Cyclic $\beta 1,2$-glucans of Brucella prevent phagosome maturation by interfering with lipid rafts, thus altering protein expression in the vacuolar membrane and excluding lysosomal proteins from the BCV [10, 103, 111].

LPS is another virulence factor of Brucella that contributes to initial survival of bacteria in macrophages [104]. LPS is essential for the functional and structural integrity of the outer membrane of gram-negative bacteria. Characterization of the LPS phenotype of Brucella spp. as smooth or rough depends on the presence or absence of the surface-exposed O-polysaccharide chain, respectively. The O-polysaccharide plays a major role in virulence associated with smooth LPS since mutant rough strains are defective for survival in macrophage cultures, as well as in vivo in mice $[104,112,113]$. Although rough mutants derived from virulent smooth Brucella mutant strains generally invade host cells more efficiently than smooth strains, they are less able to survive within the cell. However, some rough strains may be naturally virulent $[85,86]$. Intracellular replication of smooth Brucella strains may reflect the role of smooth LPS in the early development of the Brucella-containing phagosome. Brucella can block maturation of phagosome through the interaction of smooth LPS with lipid rafts, which contributes to inhibition of phagosome-lysosome fusion [79]. Furthermore, smooth LPS provides resistance to complement and antimicrobial peptides such as $\alpha$-defensins and lactoferrins [104, 114-116]. Smooth LPS also confers resistance to nitric oxide, free radicals, and lysozyme, important antibacterial mechanisms of macrophages and neutrophils [104, 112, 117-119]. Therefore, Brucella smooth LPS may be considered a virulence factor required for resistance against both extra- and intracellular antimicrobial mechanisms of the host.

There is evidence that other outer membrane components may play role as virulence factors of Brucella spp. A mutant strain of $B$. abortus lacking Omp25 is attenuated in pregnant heifers and it is not capable of replicating in bovine phagocytes and trophoblasts [120]. Conversely, Omp25 mutant strains of $B$. ovis has an impaired ability to invade non-phagocytic cells, whereas it is capable of surviving in epithelial and macrophage cell lines [121], and it is attenuated in mice [122]. Phosphatidylcholine, a common component of the eukaryotic lipid membrane, is the major phospholipid in outer membrane of Brucella and other $\alpha$ proteobacteria, whereas it is typically absent from most prokaryotes. Mutant strains unable to produce phosphatidylcholine have a reduced ability to avoid the 


\section{lumen}

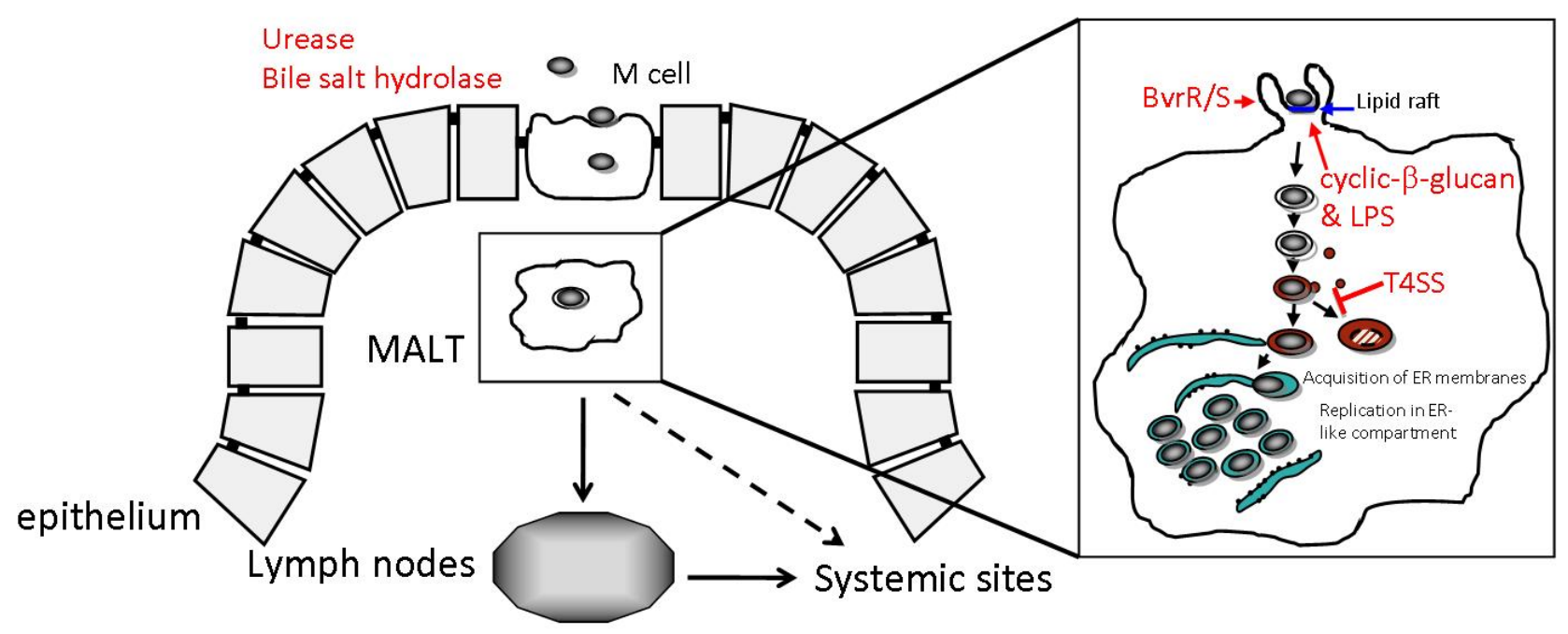

Fig. (3). Schematic representation of Brucella invasion through the digestive tract. Entry is through M cells and subsequently the bacteria are taken up by macrophages of the mucosa associated lymphoid tissue (MALT). These macrophage transport the bacteria to the lymph nodes and on to systemic sites. Blown up macrophage shows trafficking within the macrophage from entry via lipid rafts, through the endosomal pathway to the ER-like compartment in which Brucella replicates [10]. In red are Brucella virulence factors that are involved in establishing infection.

fusion with lysosomes in macrophages [123] and are attenuated in mice $[123,124]$.

The Brucella type IV secretion system (T4SS), encoded by the virB1-virB12 genes, is required for intracellular growth of Brucella in phagocytic and non-phagocytic cells [96, 125-130]. An orthologous T4SS was originally identified in the plant pathogen Agrobacterium tumefaciens, and it was later on recognized as virulence factor of animal pathogens such as Legionella pneumophila and Bordetella pertussis. The T4SS is a virulence factor characterized by a transporter apparatus localized in the outer membrane. It is able to translocate bacterial DNA or effector proteins into target host cells [125]. The T4SS of Brucella apparently does not secret DNA, and only recently some secreted molecules have been identified [131]. Effector molecules secreted by the Brucella T4SS possibly play a role in phagosome maturation and trafficking of the Brucella-containing vacuole towards its replication niche [132] since a Brucella $\operatorname{vir} B$ mutant strain is not capable of reaching the endoplasmic reticulum [14]. This critical role of the Brucella T4SS reflects in a marked impairment of persistence of vir $B$ mutant Brucella strains in vivo in both mice [129, 133], and goats [134]. Mutant Brucella strains lacking a functional T4SS have a different protein profile when compared to wild type strains [135, 136]. Furthermore, a functional T4SS may be required for induction of expression of several Brucella proteins that contribute to its virulence [136], although the mechanism by which this might occur is unknown. Although the T4SS is absolutely required for intracellular survival and replication, it is apparently not required for invasion and initial intracellular survival [64]. However, there are evidences that a $\operatorname{vir} B$ mutant strain of $B$. abortus is not capable of invading trophoblasts in vivo in pregnant mice [137].

\section{BRUCELLA AND INNATE IMMUNITY}

Interestingly, it has been demonstrated that a functional T4SS is not only required for establishment of chronic infection in mice, but it is also essential for induction of inflammatory and immune response in splenocytes of the mouse in vivo [138]. In addition, a functional T4SS is required to induce $\mathrm{B}$ cell maturation, $\mathrm{T}$ CD4+ cell activation and initial secretion of IL12 and IFN $\gamma[139,140]$. Finally, a recent study indicated that a functional T4SS is also essential for induction of microgranuloma formation in the spleen of infected mice, a typical histopathological lesion of Brucella infection [141]. Since Brucella spp. have been shown to localize to microgranulomas in infected tissue (Fig. 2A), the T4SS-induced inflammation could trigger migration of cells involved in microgranuloma formation. These microgranulomas may represent a site for persistence of Brucella in the natural host reservoir until the next breeding season.

While the T4SS elicits a low proinflammatory response, Brucella has additional strategies both to evade, and to actively prevent inflammatory responses at the site of entrance in the host. Limiting the inflammatory response to invading bacteria is likely to attenuate or delay the onset of an effective immune response, thereby allowing bacterial invasion, survival and dissemination in the host $[70,71,84$, $89,142]$. Compared to other invasive bacteria such as Salmonella spp., Brucella triggers a weak inflammatory response. Two distinct mechanisms are known to contribute to evasion of innate immunity. First, Brucella spp. produce a lipopolysaccharide that has only weak endotoxic properties, compared to that of other bacteria, which allow it to escape detection by Toll-like receptors (TLR) of the innate immune system in sentinel cells of musosal surfaces [76]. Second, Brucella can actively interfere with the generation of 
inflammatory responses by producing a protein that inhibits TLR-dependent cellular signaling pathways leading to inflammation. Since these same TLR signaling pathways are required to trigger maturation of DCs and proinflammatory cytokine/chemokine secretion, blocking this pathway is likely to affect both innate and adaptive immune responses to Brucella [70, 84]. A third immune-inhibitory activity of Brucella is the ability to block production of tumor necrosis factor alpha (TNF- $\alpha$ ) [143]. Although the molecular basis for this activity is unknown, it also seems to play a role in inhibiting DC maturation [83].

\section{PERSPECTIVE}

Brucella species are zoonotic pathogens causing persistent disease, both in the natural hosts, and in the incidental human host. Recent advances have shown that this pathogen elicits only moderate inflammatory responses, which is likely the result of strategies both to "hide" from immune detection and to actively suppress generation of host immune responses. Advances made using model systems in the laboratory have increased our understanding of pathogenic mechanisms that allow these organisms to survive in macrophages and dendritic cells--the very cells designed to eliminate invading bacteria and prime adaptive immunity. The molecular interactions with host cell components that lead to intracellular persistence are an exciting area of ongoing work. However, some questions about the biology of Brucella spp. remain to be answered, such as how the bacteria penetrate mucosal surfaces, and the molecular basis for targeting of Brucella spp. to tissues of the reproductive tract. A better understanding of these two processes may help us understand why the different Brucella species exhibit their particular host preference.

\section{ACKNOWLEDGEMENTS}

RLS and MNX are recipients of fellowships from CNPq (Conselho Nacional de Desenvolvimento Científico e Tecnológico, Brasília, Brazil). RLS is a fellow of the John Simon Guggenheim Memorial Foundation. Work in RLS lab is supported by CNPq and FAPEMIG (Fundação de Amparo a Pesquisa do Estado de Minas Gerais, Belo Horizonte, Brazil). Work in RMT's laboratory is supported by US Public Health Service grant AI050553.

\section{REFERENCES}

[1] Garrity GM. Bergey's manual of systematic bacteriology. $2^{\text {nd }}$ ed. New York: Springer 2001.

[2] Verger J, Grimont F, Grimont PAD, et al. Taxonomy of the genus Brucella. Ann Inst Pasteur Microbial 1987; 138: 235-8.

[3] Delvecchio VG, Kapatral V, Elzer P, et al. The genome of Brucella melitensis. Vet Microbiol 2002; 90: 587-92.

[4] Osterman B, Moriyon I. International Committee on Systematics of Prokaryotes Subcommittee on the taxonomy of Brucella. Int J Syst Evol Microbiol 2006; 56: 1173-5.

[5] Godfroid J, Cloeckaert A, Liautard JP, et al. From the discovery of the Malta fever's agent to the discovery of a marine reservoir, brucellosis has continuous been a re-emerging zoonosis. Vet Res 2005; 36: 313-26.

[6] Foster G, Osterman BS, Godfroid J, et al. Brucella ceti sp. nov. and Brucella pinnipedialis sp. nov. for Brucella strains with cetaceans and seals as their preferred hosts. Int J Syst Evol Microbiol 2007; 57: 2688-93.

[7] Paixão TA, Costa EA, Xavier MN, et al. Innate immunity in brucellosis. Res Adv Infect Immun 2009; 1: 21-37.
[8] Poester FP, Gonçalves VSP, Paixão TA, et al. Efficacy of strain RB51 vaccine in heifers against experimental brucellosis. Vaccine 2006; 24: 5327-34.

[9] Corbel MJ. Brucellosis: an overview. Emerg Infect Dis 2006; 3: 213-21.

[10] Starr T, Ng TW, Wehrly TD, et al. Brucella intracellular replication requires trafficking through the late endosomal/lysosomal compartment. Traffic 2008; 9: 678-94.

[11] Anderson TD, Cheville NF. Ultrastructural morphometric analysis of Brucella abortus-infected trophoblasts in experimental placentitis. Bacterial replication occurs in rough endoplasmic reticulum. Am J Pathol 1986; 124: 226-37.

[12] Anderson TD, Meador VP, Cheville NF. Pathogenesis of placentitis in the goat inoculated with Brucella abortus. II. Ultrastructural studies. Vet Pathol 1986; 23: 227-39.

[13] Pizarro-Cerdá J, Méresse S, Parton RG, et al. Brucella abortus transits through the autophagic pathway and replicates in the endoplasmic reticulum of nonprofessional phagocytes. Infect Immun 1998; 66: 5711-24.

[14] Celli J, de Chastellier C, Franchini DM, et al. Brucella evades macrophage killing via VirB-dependent sustained interactions with the endoplasmic reticulum. J Exp Med 2003; 198: 545-56.

[15] Trujillo IZ, Zavala AN, Caceres JG, et al. Brucellosis infection. Infect Dis Clin North Am 1994; 8: 225-41.

[16] Pappas G, Papadimitriou P, Akritidis N, et al. The new global map of human brucellosis. Lancet Infect Dis 2006; 6: 91-9.

[17] Fugier E, Pappas G, Gorvel JP. Virulence factors in brucellosis: implications for aetiopathogenesis and treatment. Expert Rev Mol Med 2007; 9: 1-10.

[18] Hartigan P. Human brucellosis: epidemiology and clinical manifestations. Irish Vet J 1997; 50: 179-80.

[19] Colmenero JD, Queipo-Ortuño MI, Maria Reguera J, et al. Chronic hepatosplenic abscesses in Brucellosis. Clinico-therapeutic features and molecular diagnostic approach. Diagn Microbiol Infect Dis 2002; 42: 159-67.

[20] Young EJ. An overview of human brucellosis. Clin Infect Dis $1995 ; 21: 283-9$.

[21] Verger JM, Grayon M, Zundel E, et al. Comparison of the efficacy of Brucella suis strain 2 and Brucella melitensis Rev. 1 live vaccines against a Brucella melitensis experimental infection in pregnant ewes. Vaccine 1995; 13: 191-6.

[22] Bricker BJ, Halling SM. Differentiation of Brucella abortus bv. 1, 2, and 4, Brucella melitensis, Brucella ovis, and Brucella suis bv. 1 by PCR. J Clin Microbiol 1994; 32: 2660-6.

[23] Banai M. Control of small ruminant brucellosis by use of Brucella melitensis Rev.1 vaccine: laboratory aspects and field observations. Vet Microbiol 2002; 90: 497-519.

[24] Lucero NE. Brucella isolated in humans and animals in Latin America from 1968 to 2006. Epidemiol Inf 2008; 136: 496-03.

[25] Alton GG. In: Nielsen KH, Duncan JR, Eds. Animal brucellosis. CRC: Boca Raton 1990; pp. 383-422.

[26] Kudi AC, Kalla DJU, Kudi MC, et al. Brucellosis in camels. J Arid Environ 1997; 37: 413-7.

[27] Meador VP, Deyoe BL. Intracellular localization of Brucella abortus in bovine placenta. Vet Pathol 1989; 26: 513-5.

[28] Xavier MN, Paixão TA, Poester FP, et al. Pathology, immunohistochemistry, and bacteriology of tissues and milk of cows and fetuses experimentally infected with Brucella abortus. J Comp Pathol 2009; 140: 149-57.

[29] Nicoletti P. The epidemiology of bovine brucellosis. Adv Vet Sci Comp Med 1980; 24: 69-98.

[30] Eaglesome MD, Garcia MM. Microbial agents associated with bovine genital tract infection and semen. Part I. Brucella abortus, Leptospira, Campylobacter fetus and Tritrichomonas foetus. Vet Bull 1992; 62: 743-75.

[31] Ewalt DR, Payeur JB, Rhyan JC, et al. Brucella suis biovar 1 in naturally infected cattle: A bacteriological, serological and histological study. J Vet Diagn Invest 1997; 9: 417-20.

[32] Fretin D, Whatmore AM, Al Dahouk S, et al. Brucella suis identification and biovar typing by real-time PCR. Vet Microbiol 2008; 131: 376-85.

[33] Frye, GH. Cooperative State Federal Brucellosis Eradication Program. Proc Ann Meet US Anim Health Assoc 1991; 97: 138-54.

[34] Feldman WH, Olson C. Spondylitis of swine associated with bacteria of the Brucella group. Arch Pathol 1933; 16: 195-210. 
[35] Deyoe BI. Pathogenesis of three strains of Brucella suis in swine. Am J Vet Res 1967; 28: 951-7.

[36] Vandeplassche M, Herman J, Spincemaille J, et al. Brucella suis infection and infertility in swine. Meded Veeartsenijsch Rijksuniv Gent 1967; 1: 40.

[37] Carmichael LE. In: Nielsen, K, Duncan JR, Eds. Animal brucellosis. CRC: Boca Raton 1990; pp. 335-50.

[38] Carmichael LE, Kenney RM. Canine brucellosis: the clinical disease, pathogenesis and immune response. J Am Vet Med Assoc 1970; 156: 1726-34.

[39] George LW, Duncan JR, Carmichael LE. Semen examination in dogs with canine brucellosis. Am J Vet Res 1979; 40: 1589-95.

[40] Carmichael LE, Joubert JC. Transmission of Brucella canis by contact exposure. Cornell Vet 1988; 78: 63-73.

[41] Burguess GW. Ovine contagious epididymitis: a review. Vet Microbiol 1982; 7: 551-75.

[42] Lawrence WE. Ovine brucellosis. A review of the disease in sheep manifested by epididymitis and abortion. Br Vet J 1961; 117: 43546.

[43] Cameron RDA, Lauerman JR. Characteristics of semen changes during Brucella ovis infection in rams. Vet Rec 1976; 99: 231-3.

[44] Hughes KL. Experimental Brucella ovis infection in ewe. Breeding performance of infected ewes. Aust Vet J 1972; 48: 12-7.

[45] Brown GM, Pietz DE, Price DA. Studies on the transmission of Brucella ovis infection in rams. Cornell Vet 1973; 61: 265- 80.

[46] Meinershagen WA, Frank FW, Waldhalm DG. Brucella ovis as a cause of abortion in ewes. Am J Vet Res 1974; 35: 723-4.

[47] Ewalt DR, Payeur JB, Martin BM, et al. Characteristics of a Brucella species from a bottlenose dolphin (Tursiops truncates). J Vet Diagn Invest 1994; 6: 448-52.

[48] Ross HM, Foster G, Reid RJ, et al. Brucella species infection in sea-mammals. Vet Rec 1994; 134: 359.

[49] Foster G, Jahans KL, Reid RJ, et al. Isolation of Brucella species from cetaceans, seals and an otter. Vet Rec 1996; 138: 583-6.

[50] Clavareau C, Wellemans V, Walravens K, et al. Phenotypic and molecular characterization of a Brucella strain isolated from a minke whale (Balaenoptera acutorostrata). Microbiology 1998; 144: 3267-73.

[51] Wyatt HV. Royal navy surgeons and the transmission of brucellosis by goats' milk. J R Naval Med Serv 1999; 85: 112-7.

[52] Foster G, Osterman BS, Godfroid J, et al. Brucella ceti sp. nov. and Brucella pinnipedialis sp. nov. for Brucella strains with cetaceans and seals as their preferred hosts. Int J Syst Evol Microbiol 2007; 57: 2688-93

[53] Sohn AH. Human neurobrucellosis with intracerebral granuloma caused by a marine mammal Brucella spp. Emerg Infect Dis 2003; 9: 485-8.

[54] Hernandez-Mora G, González-Barrientos R, Morales JA, et al. Neurobrucellosis in stranded dolphins, Costa Rica. Emerg Infect Dis 2008; 14: 1430-3.

[55] McDonald WL, Jamaludin R, Mackereth G, et al. Characterization of a Brucella sp. strain as a marine-mammal type despite isolation from a patient with spinal osteomyelitis in New Zealand. J Clin Microbiol 2006; 44: 4363-70.

[56] Foster G, MacMillan AP, Godfroid J, et al. A review of Brucella sp. infection of sea mammals with particular emphasis on isolates from Scotland. Vet Microbiol 2002; 90: 563-80.

[57] Miller WG, Adams LG, Ficht TA, et al. Brucella-induced abortions and infection in bottlenose dolphins (Tursiops truncatus). J Zoo Wildl Med 1999; 30: 100-10.

[58] González L, Patterson IA, Reid RJ, et al. Chronic meningoencephalitis associated with Brucella sp. infection in live-stranded striped dolphins (Stenella coeruleoalba). J Comp Pathol 2002; 126: 147-52.

[59] Rhyan, JC, Gidlewski T, Ewalt DR, et al. Seroconversion and abortion in cattle experimentally infected with Brucella sp. isolated from a Pacific harbor seal (Phoca vitulina richardsi). J Vet Diagn Invest 2001; 13: 379-82.

[60] Schlabritz-Loutsevitch NE, Whatmore AM, Quance CR, et al. A novel Brucella isolate in association with two cases of stillbirth in non-human primates - first report. J Med Primatol 2009; 38: 70-3.

[61] Stoenner HG, Lackman DB. A new species of Brucella isolated from the wood rat, Neotomae lepida. Am J Vet Res 1957; 18: 94751.
[62] Scholz HC, Hubalek Z, Sedlácek I, et al. Brucella microti sp. nov., isolated from the common vole Microtus arvalis. Int J Syst Evol 2008; 58: 375-82.

[63] Scholz HC, Hofer E, Vergnaud G, et al. Isolation of Brucella microti from mandibular lymph nodes of Red Foxes, Vulpes vulpes, in Lower Austria. Vector Borne Zoo Dis 2009; 9: 153-6.

[64] Celli J. Surviving inside a macrophage: the many ways of Brucella. Res Microbiol 2006; 157: 93-8.

[65] Pizarro-Cerdá J, Moreno E, Gorvel JP. Invasion and intracellular trafficking of Brucella abortus in non phagocytic cells. Rev Microbe Infect 2000; 2: 829-35.

[66] Ficht TA. Intracellular survival of Brucella: Defining the link with persistence. Vet Microbiol 2003; 2516: 1-11.

[67] Billard E, Cazevieille C, Dornand J, et al. High susceptibility of human dendritic cells to invasion by the intracellular pathogens Brucella suis, B. abortus, and B. melitensis. Infect Immun 2005; 73: 8418-24.

[68] Anderson TD, Meador VP, Cheville NF. Pathogenesis of placentitis in the goat inoculated with Brucella abortus. I. Gross and histologic lesions. Vet Pathol 1986; 23: 219-6.

[69] Ackermann MR, Cheville NF, Deyeoe BL. Bovine ileal dome lymphoepithelial cell: endocytosis and transport of Brucella abortus strain 19. Vet Pathol 1988; 25: 28-35.

[70] Salcedo SP, Maechesini MI, Lelouard H, et al. Brucella control of dendritic cell maturation is dependent on the TIR-containing protein Btp1. PLoS Pathog 2008; 4: e21.

[71] Paixão TA, Roux $\mathrm{CM}$, den Hartigh $\mathrm{AB}$, et al. Establishment of systemic Brucella melitensis infection through the digestive tract requires urease, the type IV secretion system, and lipopolysaccharide O-antigen. Infect Immun 2009; 77(10): 4197208.

[72] Campbell GA, Adams LG, Sowa BA. Mechanism of binding of Brucella abortus to mononuclear phagocytes from cows naturally resistant or susceptible to brucellosis. Vet Immunol Immunopathol 1994; 41: 295-306.

[73] Jones SM, Winter AJ. Survival of virulent and attenuated strains of Brucella abortus in normal and gamma interferon-activated murine peritoneal macrophages. Infect Immun 1992; 60: 3011-4.

[74] Eze MO, Yuan L, Crawford RM, et al. Effects of opsonization and gamma interferon on growth of Brucella melitensis $16 \mathrm{M}$ in mouse peritoneal macrophages in vitro. Infect Immun 2000; 68: 257-63.

[75] Kim S, Watarai M, Suzuki H, et al. Lipid raft microdomains mediate class A scavenger receptor-dependent infection of Brucella abortus. Microb Pathog 2004; 37: 11-9.

[76] Lapaque N, Forquet F, de Chastellier C, et al. Characterization of Brucella abortus lipopolysaccharide macrodomains as mega rafts. Cell Microbiol 2006; 8: 197-206.

[77] Jiang X, Leonard B, Benson R, et al. Macrophage control of Brucella abortus: role of reactive oxygen intermediates and nitric oxide. Cell Immunol 1993; 151: 309-19.

[78] Arenas GN, Staskevich AS, Aballay A, et al. Intracellular trafficking of Brucella abortus in J774 macrophages. Infect Immun 2000; 68: 4255-63

[79] Porte F, Naroeni A, Ouahrani-Bettache S, et al. Role of the Brucella suis lipopolysaccharide $\mathrm{O}$ antigen in phagosomal genesis and in inhibition of phagosome-lysosome fusion in murine macrophages. Infect Immun 2003; 71: 1481-90.

[80] Celli J, Salcedo SP, Gorvel JP. Brucella coopts the small GTPase Sar1 for intracellular replication. Proc Natl Acad Sci USA 2005; 102: $1673-8$

[81] Boschiroli ML, Ouahrani-Bettache S, Foulongne V, et al. The Brucella suis virB operon is induced intracellularly in macrophages. Proc Natl Acad Sci USA 2002; 99: 1544-9.

[82] Porte F, Liautard JP, Kohler S. Early acidification of phagosomes containing Brucella suis is essential for intracellular survival in murine macrophages. Infect Immun 1999; 67: 4041-7.

[83] Billard E, Dornand J, Gross A. Brucella suis prevents human dendritic cell maturation and antigen presentation through regulation of tumor necrosis factor alpha secretion. Infect Immun 2007; 75: 4980-9.

[84] Cirl C, Wieser A, Yadav M, et al. Subversion of Toll-like receptor signaling by a unique family of bacterial Toll/interleukin-1 receptor domain-containing proteins. Nat Med 2008; 14: 399-406.

[85] Detilleux PG, Deyoe BL, Cheville NF. Penetration and intracellular growth of Brucella abortus in non phagocytic cells in vitro. Infect Immun 1990; 58: 2320-8. 
[86] Detilleux PG, Deyoe BL, Cheville, NF. Entry and intracellular localization of Brucella spp. in Vero cells: fluorescence and electron microscopy. Vet Pathol 1990; 27: 317-28.

[87] Pizarro-Cerdá J, Moreno E, Sanguedolce V, et al. Virulent Brucella abortus prevents lysosome fusion and is distributed within autophagosome-like compartments. Infect Immun 1998; 66: 238792.

[88] Guzmán-Verri C, Chaves-Olarte E, Von Eichel-Streiber C, et al. GTPases of the Rho subfamily are required for Brucella abortus internalization in non professional phagocytes: direct activation of CDC42. J Bio Chem 2001; 276: 44435-43.

[89] Neta CAV, Steynen APR, Paixão TA, et al. Modulation of bovine trophoblastic innate immune response by Brucella abortus. Infect Immun 2008; 76: 1897-907.

[90] Watanabe K, Tachibana M, Tanaka S, et al. Heat shock cognate protein 70 contributes to Brucella invasion into trophoblast giant cells that cause infectious abortion. BMC Microbiol 2008; 8: 212.

[91] Santos RL, Baumler AJ. Cell tropism of Salmonella enterica. Int J Med Microbiol 2004; 294: 225-33.

[92] Kim S, Watarai M, Kondo Y, et al. Isolation and characterization of mini-Tn5 $\mathrm{Km} 2$ insertion mutants of Brucella abortus deficient in internalization and intracellular growth in HeLa cells. Infect Immun 2003; 71: 3020-7.

[93] Castañeda-Roldán OU, Ahrani-Bettache S, Saldaña Z, et al. Characterization of SP41, a surface protein of Brucella associated with adherence and invasion of host epithelial cells. Cell Microbiol 2006; 8: 1877-87.

[94] Hernández-Castro R, Verdugo-Rodríguez A, Puente JL, et al. The BMEI0216 gene of Brucella melitensis is required for internalization in HeLa cells. Microb Pathog 2008; 44: 28-33.

[95] Chaves-Olarte E, Guzmán-Verri C, Méresse S, et al. Activation of Rho and Rab GTPases dissociate Brucella abortus internalization from intracellular trafficking. Cell Microbiol 2002; 4: 663-76.

[96] Comerci DJ, Martinez-Lorenzo MJ, Sieira R, et al. Essential role of the VirB machinery in the maturation of the Brucella abortuscontaining vacuole. Cell Microbiol 2001; 3: 159-68.

[97] Samartino LE, Traux RE, Enright F. Invasion and replication of Brucella abortus in three different trophoblastic cell lines. Zentralbl Veterinarmed B 1994; 41: 229-36.

[98] Samartino LE, Enright FM. Brucella abortus differs in the multiplication within bovine chorioallantoic membrane explants from early and late gestation. Comp Immunol Microbiol Infect Dis 1996; 19: 55-63.

[99] Samartino LE, Enright FM. Pathogenesis of abortion of bovine brucellosis. Comp Immunol Microbiol Infect Dis 1993; 16: 95-101.

[100] Gorvel JP, Moreno E. Brucella intracellular life: from invasion to intracellular replication. Vet Microbiol 2002; 90: 281-97.

[101] Moreno E, Moriyón I. In: Dworking M, Falkow S, Rosemberg E, Schleifer KH, Stackebrandt E, Eds. The Prokaryotes, Springer: New York 2001 (Electronic version).

[102] López-Goñi I, Guzmán-Verri C, Manterola L, et al. Regulation of Brucella virulence by the two-component system BvrR/BvrS. Vet Microbiol 2002; 90: 329-39.

[103] Arellano-Reynoso B, Lapaque N, Salcedo S, et al. Cyclic beta-1, 2glucan is a Brucella virulence factor required for intracellular survival. Nat Immun 2005; 6: 618-63.

[104] Lapaque N, Moriyon I, Moreno E, et al. Brucella lipopolysaccharide acts as a virulence factor. Curr Opin Microbiol 2005; 8: 60-6.

[105] Bandara AB, Contreras A, Contreras-Rodriguez A, et al. Brucella suis urease encoded by ure 1 but not ure 2 is necessary for intestinal infection of BALB/c mice. BMC Microbiol 2007; 7: 57.

[106] Sangari FJ, Seoane A, Rodríguez MC, et al. Characterization of the urease operon of Brucella abortus and assessment of its role in virulence of the bacterium. Infect Immun 2007; 75: 774-80.

[107] Delpino MV, Marchesini MI, Estein SM, et al. A bile salt hydrolase of Brucella abortus contributes to the establishment of a successful infection through the oral route in mice. Infect Immun 2007; 75: 299-305.

[108] Collins CM, D'Orazio SE. Bacterial ureases: structure, regulation of 42 expression and role in pathogenesis. Mol Microbiol 1993; 9: 907-13.

[109] Guzmán-Verri C, Manterola L, Sola-Landa A, et al. The twocomponent system BvrR-BvrS essential for Brucella abortus virulence regulates the expression of the outer membrane proteins with counterparts in members of the Rizhobiaceae. Proc Natl Acad Sci USA 2002; 99 : 12375-80.

[110] Sola-Landa A, Pizarro-Cerdá J, Griló MJ, et al. A two-component regulatory system playing a critical role in plant pathogens and endosymbionts is present in Brucella abortus and controls cell invasion and virulence. Mol Microbiol 1998; 29: 125-38.

[111] Briones G, Iñón de Iannino N, Roset M, et al. Brucella abortus cyclic beta-1, 2-glucan mutants have reduced virulence in mice and are defective in intracellular replication in HeLa cells. Infect Immun 2001; 69: 4528-35

[112] Allen CA, Adams LG, Ficht TA. Transposon-derived Brucella abortus rough mutants are attenuated and exhibit reduced intracellular survival. Infect Immun 1998; 66: 1008-16.

[113] Jimenez de Bagues MP, Terraza A, Gross A, et al. Different responses of macrophages to smooth and rough Brucella spp.: relationship to virulence. Infect Immun 2004; 72: 2429-33.

[114] de Tejada MG, Pizarro-Cerdá J, Moreno E, et al. The outer membranes of Brucella spp. are resistant to bactericidal cationic peptides. Infect Immun 1995; 63: 3054-61.

[115] Fernandez-Prada CM, Nikolich M, Vemulapalli R, et al. Deletion of wboA enhances activation of the lectin pathway of complement in Brucella abortus and Brucella melitensis. Infect Immun 2001; 69: 4407-16.

[116] Tumurkhuu G, Koide N, Takahashi K, et al. Characterization of biological activities of Brucella melitensis lipopolysaccharide. Microbiol Immunol 2006; 50: 421-7.

[117] Riley LK, Robertson DC. Ingestion and intracellular survival of Brucella abortus in human and bovine polymorphonuclear leukocytes. Infect Immun 1984; 46: 224-30.

[118] Rasool O, Freer E, Moreno E, et al. Effect of Brucella abortus lipopolysaccharide on oxidative metabolism and lysozyme release by human neutrophils. Infect Immun 1992; 60: 1699-702.

[119] Fernandez-Prada CM, Zelazowska EB, Nikolich M, et al. Interactions between Brucella melitensis and human phagocytes: bacterial surface O-Polysaccharide inhibits phagocytosis, bacterial killing, and subsequent host cell apoptosis. Infect Immun 2003; 71: 2110-9.

[120] Edmonds MD, Cloeckaert A, Booth NJ, et al. Attenuation of a Brucella abortus mutant lacking a major $25 \mathrm{kDa}$ outer membrane protein in cattle. Am J Vet Res 2001; 62: 1461-6.

[121] Martín-Martín AI, Caro-Hernández P, Orduña A, et al. Importance of the Omp25/Omp31 family in the internalization and intracellular replication of virulent $B$. ovis in murine macrophages and $\mathrm{HeLa}$ cells. Microbes Infect 2008; 10: 706-10

[122] Caro-Hernández P, Fernández-Lago L, de Miguel MJ, et al. Role of the Omp25/Omp31 family in outer membrane properties and virulence of Brucella ovis. Infect Immun 2007; 75: 4050-61.

[123] Conde-Alvarez R, Grilló MJ, Salcedo SP, et al. Synthesis of phosphatidylcholine, a typical eukaryotic phospholipid, is necessary for full virulence of the intracellular bacterial parasite Brucella abortus. Cell Microbiol 2006; 8: 1322-35.

[124] Comerci DJ, Altabe S, de Mendoza D, et al. Brucella abortus synthesizes phosphatidylcholine from choline provided by the host. J Bacteriol 2006; 188: 1929-34.

[125] O'Callaghan D, Cazevieille C, Allardet-Servent A, et al. A homologue of the Agrobacterium tumefaciens VirB and Bordetella pertussis Ptl type IV secretion systems is essential for intracellular survival of Brucella suis. Mol Microbiol 1999; 33: 1210-20.

[126] Sieira R, Comerci DJ, Sanchez DO, et al. A homologue of an operon required for DNA transfer in Agrobacterium is required in Brucella abortus for virulence and intracellular multiplication. J Bacteriol 2000; 182: 849-55.

[127] Delrue RM, Martinez-Lorenzo M, Lestrate P, et al. Identification of Brucella spp. genes involved in intracellular trafficking. Cell Microbiol 2001; 3: 487-97.

[128] Sun YH, Den Hartigh AB, Santos RL, et al. Vir-B mediated survival of Brucella abortus in mice and macrophages is independent of a functional inducible nitric oxide synthase or macrophage NADPH oxidase in macrophages. Infect Immun 2002; 70: 4826-32.

[129] den Hartigh AB, Sun YH, Van Sonder D, et al. Differential requirements for VirB1 and VirB2 during Brucella abortus infection. Infect Immun 2004; 72: 5119-43.

[130] den Hartigh AB, Rolán HG, De Jong MF, et al. VirB3 to VirB6 and VirB8 to VirB11, but not VirB7, are essential for mediating 
persistence of Brucella in the reticuloendothelial system. J Bacteriol 2008; 90: 4427-36.

[131] de Jong MF, Sun YH, den Hartigh AB, et al. Identification of VceA and VceC, two members of the VjbR regulon that are translocated into macrophages by the Brucella type IV secretion system. Mol Microbiol 2008; 70: 1378-96.

[132] Boschiroli ML, Ouahrani-Bettache S, Foulongne, V. Type IV secretion and Brucella virulence. Vet Microbiol 2002; 90: 341-8.

[133] Hong PC, Tsolis RM, Ficht TA. Identification of genes required for chronic persistence of Brucella abortus in mice. Infect Immun 2000; 68: 4102-7.

[134] Zygmunt MS, Hagius SD, Walker JV, et al. Identification of Brucella melitensis $16 \mathrm{M}$ genes required for bacterial survival in the caprine host. Microbes Infect 2006; 8: 2849-54.

[135] Delpino MV, Comerci DJ, Wagner MA, et al. Differential composition of culture supernatants from wild-type Brucella abortus and its isogenic virB mutants. Arch Microbiol 2009; 191: 571-81.

[136] Wang Y, Chen Z, Qiao F, et al. Comparative proteomics analyses reveal the virB of $B$. melitensis affects expression of intracellular survival related proteins. PLoS One 2009; 4: e5368.
[137] Kim S, Lee DS, Watanabe K, et al. Interferon-gamma promotes abortion due to Brucella infection in pregnant mice. BMC Microbiol 2005; 5: 22

[138] Roux CM, Rolán HG, Santos RL, et al. Brucella requires a functional Type IV secretion system to elicit innate immune responses in mice. Cell Microbiol 2007; 9: 1851-69.

[139] Rolán HG, Tsolis RM. Mice lacking components of adaptive immunity show increased Brucella abortus virB mutant colonization. Infect Immun 2007; 75: 2965-73.

[140] Rolán HG, Tsolis RM. Inactivation of the type IV secretion system reduces the Th1 polarization of the immune response to Brucella abortus infection. Infect Immun 2008; 76: 3207-13.

[141] Rolán HG, Xavier MN, Santos RL, et al. Natural antibody contributes to host defense against an attenuated Brucella abortus virB mutant. Infect Immun 2009; 77: 3004-13.

[142] Barquero-Calvo E, Chaves-Olarte E, Weiss DS, et al. Brucella abortus uses a stealthy strategy to avoid activation of the innate immune system during the onset of infection. PLoS One 2007; 18 : e7.

[143] Caron E, Gross A, Liautard JP, et al. Brucella species release a specific, protease sensitive inhibitor of TNF expression, active on human macrophage-like cells. J Immunol 1996; 156: 2885-93.

(C) Xavier et al.; Licensee Bentham Open.

This is an open access article licensed under the terms of the Creative Commons Attribution Non-Commercial License (http://creativecommons.org/licenses/by-nc/ $3.0 /$ ) which permits unrestricted, non-commercial use, distribution and reproduction in any medium, provided the work is properly cited 